Research Article

\title{
Coordinated Operation of the Constituent Components of a Community Energy System to Maximize Benefits While considering the Network Constraints
}

\author{
A. H. Wijethunge $\mathbb{i D}^{1,2}$ J. V. Wijayakulasooriya, ${ }^{1}$ J. B. Ekanayake, ${ }^{1}$ and A. Polpitiya ${ }^{2}$ \\ ${ }^{1}$ Department of Electrical and Electronic Eng., University of Peradeniya, Peradeniya, Sri Lanka \\ ${ }^{2}$ Sri Lanka Technological Campus, Padduka, Sri Lanka
}

Correspondence should be addressed to A. H. Wijethunge; aki.wijethunga@gmail.com

Received 7 March 2019; Revised 29 April 2019; Accepted 23 May 2019; Published 24 June 2019

Academic Editor: Salvatore Favuzza

Copyright (c) 2019 A. H. Wijethunge et al. This is an open access article distributed under the Creative Commons Attribution License, which permits unrestricted use, distribution, and reproduction in any medium, provided the original work is properly cited.

\begin{abstract}
Smart community with locally generated renewable energy is a new paradigm that leads to a system that is more sustainable, secure, and cost-effective to the community while enabling connection of more distributed energy resources. In this paper, a method to maximize the utilization of the renewables while maximizing the profit of a smart community within system constraints was suggested by introducing an optimum schedule of smart appliances in the community. Further dynamic line rating of the network connection is considered to investigate the advantage of using the dynamic rating against static rating. Different operating modes based on the variations of available renewable energy generation, wind speed, tariff, grid curtailment, and user preferences were investigated. A modified genetic algorithm-based optimization was implemented to obtain the optimum smart community's appliance schedule. The optimum appliance schedules were obtained considering different case studies representing possible operating modes of the system. The simulations show that the use of dynamic line rating and optimum appliance schedule provide higher profit to the community. The algorithm managed to run the optimization with 12,500 controllable entities within an average execution time of 2000 s.
\end{abstract}

\section{Introduction}

There is a growing interest for the community energy projects that have an emphasis on local engagement, local leadership and control, and the local community benefiting collectively from the outcomes [1]. Community power will create a new paradigm that is a locally controlled energy system with distribution technologies and market mechanisms. This paradigm leads to a system that is more sustainable, secure, and cost-effective to the community while enabling connection of more and more renewable-based distributed energy resources. In community energy systems, where the loads and generation both are dynamic, increasing the self-utilization of renewable energy and reducing the peak load in the domestic sector via a localized demand side management system is important [2].
Numerous operational paradigms and market mechanism are reported in the literature for the community energy/power system. An energy management system to schedule consumers based on dynamic pricing where consumers act as prosumers (produce energy and consume energy) is introduced in Kitakyushu Smart Community Creation Project [3, 4]. A self-sustainable community system comprises prosumers where the locally generated energy is consumed to match the demand by self-supply and selforganized trade among sellers and buyers, and imported power from the local market for prosumers is presented in [5]. As a different approach, a distributed load scheduling scheme without overrevealing consumer power consumption for a smart community connected to utility and smallscale local supplier is introduced in [6]. Additionally, an optimal scheduling method of distributed generation and 
residential loads to reduce customer electricity and reduce the peak load for a smart community comprises interruptible loads, controllable loads, and roof-top solar panels, and storage based on load and generation dispatching without discomforting the user is introduced in [7].

Relevant control policies such as (a) the price control mechanism to discourage noncollaborative behaviors of renewable energy generation in order to optimize renewable generation output without shifting load, (b) the power flow control method to avoid peak loads using DSM and energy storage to save the annual energy cost of a grid-connected community with high PV penetration, (c) the feed-in tariff mechanism for the PV customers to reduce peak demand and increase self-consumption of PV generation, and (d) a real-time pricing based on wholesale market were also introduced as operational paradigms for the community energy/power system $[8,9]$. The peak-to-average reduction (PAR) by community-based to increase the community interaction among households by sharing individual usage and scheduling the appliances by considering the surrounding community consumption patterns is considered [10]. In a different study, the peak-to-average ratio is minimized at minimum power generation cost via demand side management by motivating consumers who own storage using a dynamic price [11].

In addition to the above studies, optimum management of electrical power and energy within small communities is achieved using the community power flow target (CPFT) technique [12]. Furthermore, an optimum schedule to minimize cost is achieved by trading electricity through a local flexible market in a community system with renewable energy providers and prosumers [13]. Moreover, collaborative actions of prosumer community groups are inspired in order to achieve multiple goals such as demand constraints, cost constraints, and income maximization [14, 15].

In order to achieve the abovementioned operational paradigms and market mechanisms, different optimization techniques such as linear optimization, game theory-based optimization, and heuristic methods of optimization are used in community energy systems.

A linear optimization method is suggested in [16] to obtain the optimum schedule for prosumers controlled by the aggregator who only controls 200 water heater loads to maximize the benefit to the whole prosumer population and minimize the imbalance cost of the aggregator. Similarly, the linear optimization is used to minimize cost and peak demand subjected to comfort constraints of a single house containing battery storage, water heaters, and air conditioners [17]. Receding horizon optimization method is used in [18] to obtain the optimum usage of renewable sources (solar, wind, diesel generator, and storage) of a single household along with demand response to minimize the cost over a moving time horizon.

An ordinal state-based potential game approach is used to minimize the total energy purchase for a residential smart grid considering thermal limits of feeders and transformers without a central coordinator [19]. This system considers energy provider as an external party. An artificial neural network model is used to maximize the self-consumption of
PV of a house with PV generation, storage, grid connection, and smart appliances [20]. Based on multiobjective decisionmaking methodology, the cost of the distributed network is minimized by reducing the peak load while preventing overloading of network and transformers at peak demand [21].

Heuristic optimization methods provide a better solution approach for combinatorial optimization problems of energy management in community power systems [22, 23]. The greedy algorithm-based load shifting mechanism is used to achieve a solution closer to the optimum solution to improve the self-consumption of PV generation in 200 Swedish households [24]. Greedy algorithm is also used to schedule the heater, CHP, and storage while considering uncontrolled appliances according to their flexibility to minimize the power exchange with the grid while achieving local supply and demand matching [25]. Additionally, different metaheuristic methods are used for the optimization of an energy resource management system with controllable variables such as demand response, electric vehicle, and storage to maximize the profit [23].

Genetic algorithm (GA) is a widely used heuristic optimization method to achieve operational paradigms in community energy systems. GA-based method is used for single and multiple objective optimization to match distribution system's controlled resources with the operator's objectives based on controlled resources sensitivities and operational costs [26]. Furthermore, GA is applied to identify the optimum shifting of a load block (part of the load profile) to reduce peak load while ensuring the minimum disruption to the commercial and residential loads [27]. GA is also used to optimize three objective functions, namely, minimized operational cost, minimized operational unsafely, and minimized operational delays using an energy management system [28]. Moreover, GA-based model is used for the optimization of the profit of an aggregator which decides day-ahead customer incentive price (CIP) and the schedule of the customers [29].

Even though the numerous operational paradigms and market mechanism and optimization techniques are described in the literature, the following limitations are identified.

None of the studies considers operational mechanisms that ensure the maximum utilization of the line capacity between the community system and DNO. At present, the line capacity of the existing lines is determined conservatively [30,31]. In practice, the conductor current capacity is determined based on the maximum allowable temperature and the worst case scenario for weather and other conditions [31]. Practically, the worst conditions rarely occur. This artificial bottleneck created by the line capacity hinders efficient utilization of assets and the cost-effective and efficient operation of the community energy project.

The optimization problem associated with a community energy system requires a complex mathematical model to represent real-world random processes and to execute with a large number of variables. Except in references [23, 29, 32], in most of the above studies, a single house or a limited number of houses with controllable loads were considered. 
However, none of them considered a large number of controllable entities within a single distribution network that requires robust optimization tools and a less computation time.

One of the main contributions of this paper is determining an optimum operating paradigm based on the DSM of community loads and the dynamic line rating of the network connection thus maximizing the profit to the community. The scheduling of noncritical loads of each premise was considered while ensuring user preferences, dynamic line rating of the utility connection, and renewable generation within the community.

Another contribution of this paper is the introduction of an optimization algorithm that requires a comparatively low computational time for a system having a large number of houses with many controllable appliances, thus controlling a larger number of controllable entities. This optimization problem is a combinatorial problem which also has a dynamic feasible region of the solution space.

In summary, the key contributions of this paper are as follows:

(1) Introducing a method for obtaining the appliance schedule at the maximum profit of a smart community who has its own renewable energy generation based on a modified genetic algorithm

(2) Investigate the benefit of dynamic line rating of the utility connection against static rating that ensures the maximum utilization of the line capacity between the community system and network operator

The paper is organized as follows. Section 2 provides a formulation of the methodology of optimization of the community energy system using the genetic algorithm. Section 3 presents the development of the case study. Section 4 provides the results and discussion with simulation studies for the proposed approaches, and Section 5 concludes the paper.

\section{Methodology}

2.1. Community Energy System. A generic system of a smart community is given in Figure 1. The following assumptions were made:

(a) The consumers are collaboratively participating in DSM activities which ensure the optimum profit is achieved

(b) All the reactive power requirement of the community loads is fully compensated by the smart inverters of the renewable energy sources; thus, only active power balance and the cost of active power transfer are considered.

The operating paradigm assumed was maximizing the profit to the community or minimizing the cost of consumption within the community while satisfying the operational constraints. The grid connection allows the consumers to export excess of renewable energy or import any required power to satisfy the demand.
2.2. Appliance Schedule and Total Demand. It was assumed that the $n$th house has $A_{\mathrm{n}}$ number of appliances. The $a p$ pliance schedule is defined as $X$ for all $N$ houses in 24 hours as in equation (1). In order to generate this schedule, it was assumed that 24 hours of a day is equally divided into $T$ number of operating time slots:

$$
\begin{aligned}
X=\left\{\ldots,\left[x_{a_{n}^{1}}^{h} \ldots x_{a_{n}^{y}}^{h} \ldots x_{a_{n}^{A_{n}}}^{h}\right], \ldots\right\}, & \\
X & \text { is a matrix of size }\left\{1,\left[\left(\sum_{n=1}^{N} A_{n}\right) \times T\right]\right\},
\end{aligned}
$$

where $h=(24 / T), 2 \times(24 / T), \ldots, 24, x_{a_{n}^{y}}^{h} \in\{1,0\}$.

The power demand at time slot $h$ is defined by $D^{h}$ as follows:

$$
D^{h}=\sum_{n=1}^{N} \sum_{y=1}^{A_{n}}\left(P_{y, n}^{h} \times x_{a_{n}^{y}}^{h}\right) .
$$

2.3. Operational Modes. According to the operating conditions of the system shown in Figure 1, three operational modes were identified and given in Table 1 . In each time slot $h, \sum_{k=1}^{k} P_{\mathrm{RE}_{k}}^{h}$ is the total power generation from all renewable energy sources, $D^{h}$ is the total demand of the smart community, $P_{\text {export }}^{h}$ is the maximum power that can be exported to grid from community renewable energy sources when grid curtailment is active, $P_{\max }^{h}$ is the maximum active power rating of the conductor $\mathrm{A}-\mathrm{B}$ (Figure 1), $P_{\text {Conductor }}^{h}$ is the actual power transferred through the conductor A-B, and $P_{\text {excess }}^{h}$ is $\sum_{k=1}^{k} P_{\mathrm{RE}_{k}}^{h}-D^{h}$. These operating modes introduce dynamic constraints that create a dynamic feasible region for the solution space of the optimization problem.

For each time slot $h$, the operating mode of the system is identified based on Table 1. The optimization algorithm decides the optimum operating point of the system for each time slot to minimize the cost within the system constraints.

In Mode 1, it is possible to send the total excess power generation from renewable energy sources after selfconsumption to the grid if $P_{\max }^{h}>P_{\text {excess }}^{h}$. If $P_{\text {export }}^{h}<P_{\text {excess }}^{h}$ which limits the power exported to the grid, more smart appliances are scheduled to be operated within that time slot or renewable generation is curtailed. The excess power transfer in conductor A-B is reduced based on the conductor power rating when $P_{\max }^{h} \leq P_{\text {excess }}^{h}$ even though $P_{\text {export }}^{h}>$ $P_{\text {excess. }}^{h}$. This is achieved by curtailing or switching off the least profitable renewable generators or scheduling more smart appliances to increase the self-consumption of renewable power generation.

In Mode 2, when the total power generation from renewable energy sources is insufficient to satisfy the demand, the additional power is taken from the grid while considering the conductor power rating.

In Mode 3, too much demand is scheduled such that the capability of the line is exceeded and there is not enough renewable generation to supply the load. This condition is avoided by properly scheduling the noncritical appliances, and thus, the operation is moved into Modes 1 and 2 . 


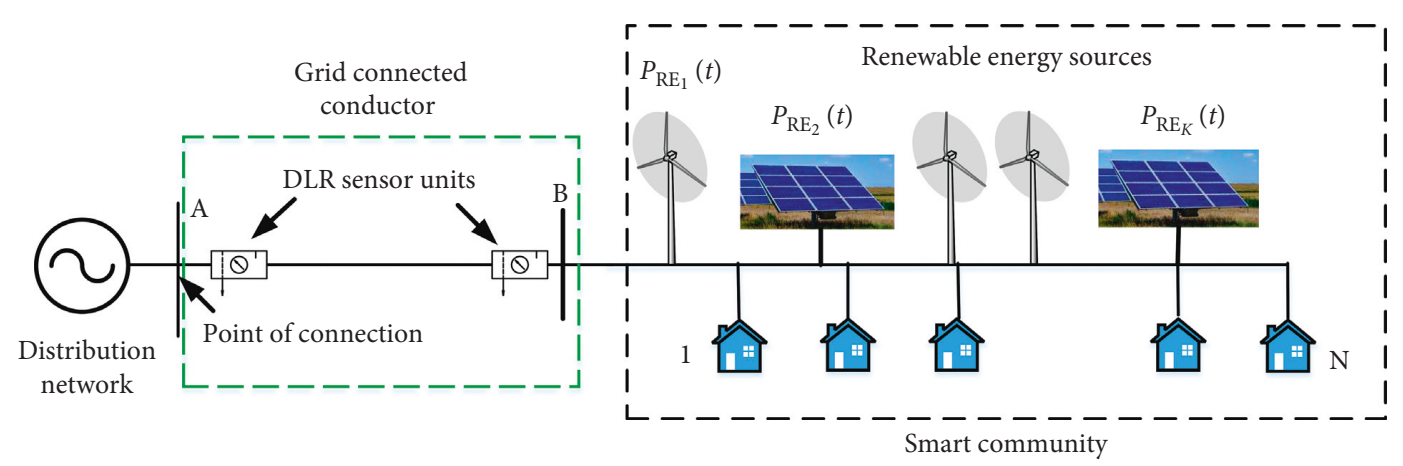

FIGURE 1: Smart community with grid connection.

TABLE 1: System operation cases.

(i) Power flow towards the grid

$$
\begin{gathered}
\text { Mode } 1 \\
D^{h} \leq \sum_{k=1}^{k} P_{\mathrm{RE}_{k}}^{h}
\end{gathered}
$$

(ii) Excess renewable power generation is sold to the grid

(iii) The power sold to the grid $\left(P_{\text {cable_sell }}^{h}\right)$ is obtained from the minimum power value from $P_{\text {excess }}^{h}, P_{\text {export }}^{h}$, and $P_{\max }^{h}$

$$
\begin{gathered}
P_{\text {conductor_sell }}^{h}=\min \left(P_{\text {excess }}^{h}, P_{\text {export }}^{h}, P_{\text {max }}^{h}\right) \\
\text { Mode } 2 \\
D^{h}>\sum_{k=1}^{k} P_{\mathrm{RE}_{k}}^{h} \text { and } P_{\max }^{h}>P_{\text {excess }}^{h}
\end{gathered}
$$

(i) Power flow from the grid to the community

(ii) Additional power is purchased from the grid

(iii) The amount of power purchased from the grid is $P_{\text {cable_buy }}^{h}$

$$
\begin{gathered}
P_{\text {conductor_buy }}^{h}=P_{\text {excess }}^{h} \\
\text { Mode } 3 \\
D^{h}>\sum_{k=1}^{k} P_{\mathrm{RE}_{k}}^{h} \text { and } P_{\text {max }}^{h}<P_{\text {excess }}^{h}
\end{gathered}
$$

(i) Not a valid operating condition

(ii) Reduce power flow in the cable by shifting smart appliances; this will revert to Modes 1 or 2 .

The above three modes were executed by considering a range of constraints defined in Section 2.4 onwards. The cost of the community for time slot $h$ was calculated using equations (3), (4), and (5). As Mode 3 is not a valid operating condition, it was avoided by assigning a maximum cost for that mode. This was achieved by multiplying the cost function by a factor of 2 .

For the system operating in Mode 1,

$$
C_{\text {community }}^{h}=-\min \left(P_{\text {excess }}^{h}, P_{\text {export }}^{h}, P_{\max }^{h}\right) C_{\mathrm{RE}}^{h} .
$$

For the system operating at Mode 2,

$$
C_{\text {community }}^{h}=\left\{C_{\mathrm{G}}^{h} \times\left[D^{h}-\sum_{k=1}^{K} P_{\mathrm{RE}_{k}}^{h}\right]\right\} .
$$

For the system operating at Mode 3,

$$
C_{\text {community }}^{h}=2 \times\left\{C_{\mathrm{G}}^{h} \times\left[D^{h}-\sum_{k=1}^{K} P_{\mathrm{RE}_{k}}^{h}\right]\right\} .
$$

The total cost of the community for the day is given by the following equation:

$$
C_{\text {community }}=\left[\sum_{h=1}^{T} C_{\text {community }}^{h}\right] \times \frac{24}{T} .
$$

2.4. Operational Constraints Considered. The appliance schedule of the community at the minimum cost or maximum profit was obtained by developing an optimization algorithm. In this algorithm, the constraints given in Table 2 were considered for each constituent component.

The algorithm given in Figure 2 was used to obtain the optimum appliance schedule at minimum cost while considering the constraints given in Table 2. Details of constraints used for the optimization algorithm is given in Sections 2.5 (A), 2.6 (B), 2.7 (C), and 2.8 (D).

2.5. Initialization of Appliance Schedule. The initial appliance schedule defined in Section 2.2 must ensure user comfort. According to their preferences, the consumer will provide the smart appliances that should be operated and the preferred operating times or time range within the day. Each house has a different number and type of smart appliances operated within the time slot $h$. It was assumed that the appliances are not interrupted during the operating cycle.

Once the consumer priority list (this could be the start time of an appliance, the maximum time period between the start and stop time of an appliance, etc.) is given, the appliance schedule is initialized. The constraint given in the following equation was used to define the ON/OFF state of the appliance: 
TABLE 2: Constraints considered.

\begin{tabular}{lc}
\hline Constituent component & Constraints \\
Grid connection & $\begin{array}{c}\text { (i) Conductor current rating } \\
\text { (ii) Voltage limits }\end{array}$ \\
$\begin{array}{lc}\text { Consumer appliances } \\
\text { Renewable energy sources }\end{array}$ & $\begin{array}{c}\text { (iii) Limitations for renewable energy import } \\
\text { (i) User preferences }\end{array}$ \\
(i) Possible power generation
\end{tabular}

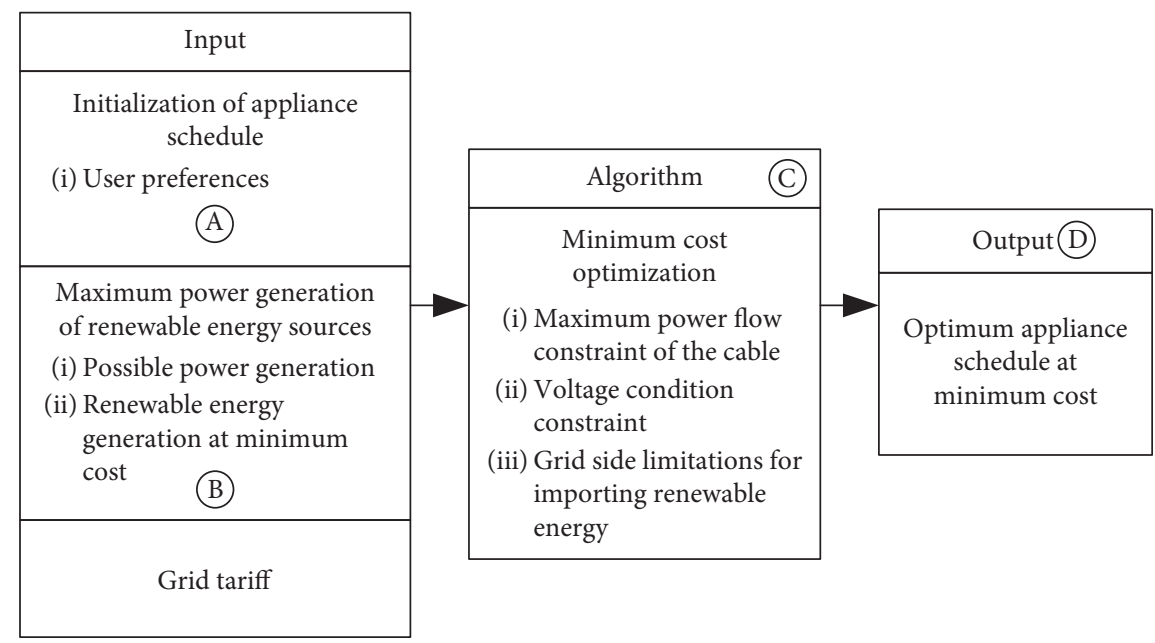

FIgURE 2: Optimization algorithm flow.

$$
\text { for } X_{a_{n}^{y}}^{h}: h_{\text {start }}<h<h_{\text {stop }}
$$

where $X^{h}=\left\{\left[X_{a_{n}^{y}}^{h}\right]_{i}\right\} i$ is the index of the appliance $a_{n}^{y}$ within $h$ time slot defined using user preferences.

For all $N$ houses, the order of operation of appliances was sorted according to the user preferences. Then, the initial appliance schedules were generated. The matrix of appliance schedule is represented as in Figure 3.

Considering the appliance's ON/OFF state for the time slot $h$ for $n$th house with $A_{n}$ appliances, the algorithm defines the operating order by considering the user preferences and the cost/profit to the community.

2.6. Constraints for Power Generation of Renewable Sources. The following constraints were considered for the renewable energy sources:

2.6.1. Operating Power Limits of Renewable Energy Sources. Each renewable energy generator has the maximum generation capacity and minimum generation capacity constraints at each time slot $h$ as given in equation (8). $P_{\mathrm{RE}_{k} \text {, } \max }^{h}$ is often based on the weather predictions, whereas $P_{\mathrm{RE}_{k} \text {, min }}^{h}$ is a technology-specific constraint:

$$
P_{\mathrm{RE}_{k}, \min }^{h}<P_{\mathrm{RE}_{k}}^{h}<P_{\mathrm{RE}_{k}, \max }^{h} \cdot
$$

2.7. Distribution Network Constraints. The following system constraints were considered:

2.7.1. Dynamic Line Rating Constraint. The current carrying capacity of a power line dynamically changes with the weather conditions. It is significantly affected by the wind speed [31], and as the wind speed increases, the dynamic line rating increases. Ambient temperature also has a large effect on conductor dynamic line rating as it affects the convection heat transfer, radiation heat transfer, and resistance [31]. As the wind and ambient temperature vary from time to time, there is always room for loading the line without violating its actual rating. This requires sensing parameters such as conductor temperature and weather conditions and then determining the line capacity dynamically. Among the available dynamic line rating systems, measuring conductor temperature, ambient temperature, wind speed, and current in real time is suggested in some of the studies [33-35].

The dynamic line rating or the maximum real-time current capacity of conductor section A-B in Figure 1 was calculated using equation (9) [36]. The exact procedure to calculate $I_{\mathrm{dyn}}^{h}$ and different parameters of the equation is given in an author's previous paper [37]: 


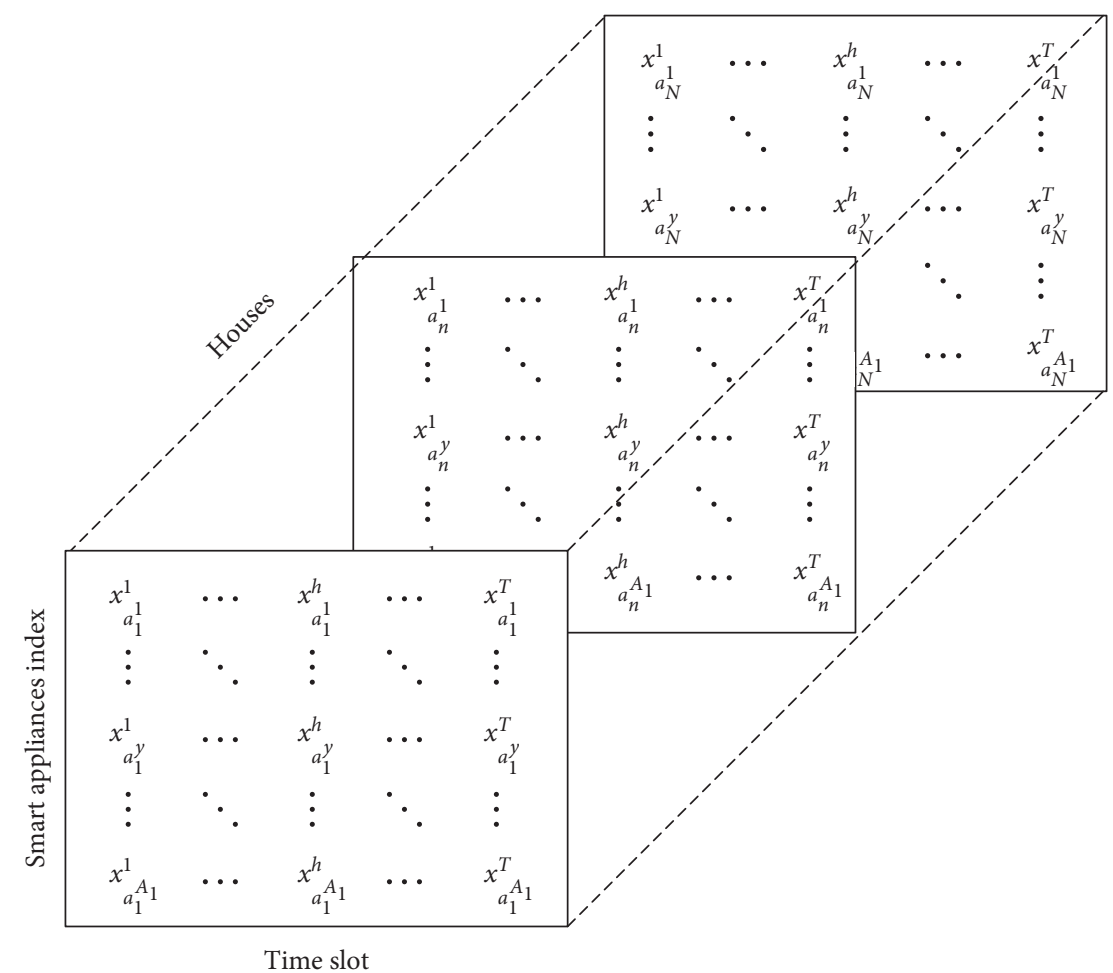

Figure 3: Appliances schedule matrix for the smart community for a day.

$I_{\mathrm{dyn}}^{h}=\sqrt{\frac{\left[\pi \lambda k_{\text {wd }}\left(T_{\max }-T_{\mathrm{a}}^{h}\right)\left(0.64\left(D\left(\left(W_{\text {conductor }}^{h}\right) /\left(V_{\mathrm{f}}\right)\right)\right)^{0.2}+0.2\left(D\left(\left(W_{\text {conductor }}^{h}\right) /\left(V_{\mathrm{f}}\right)\right)\right)^{0.61}\right)\right]+\left[\sigma \varepsilon \pi D\left(\left(T_{\max }+273\right)^{4}-\left(T_{\mathrm{a}}^{h}+273\right)^{4}\right)\right]-\left[\alpha_{\mathrm{s}} D\left(S_{\mathrm{b}}+S_{\mathrm{d}}\right)\right]}{R_{\mathrm{dc}}\left(1+\alpha_{0}\left(T_{\max }-T_{0}\right)\right)}}$.

The dynamic line rating varies with the weather conditions and that introduces a new maximum power constraint of the conductor at each time slot $h$ and is given in the following equation:

$$
P_{\mathrm{dyn}}^{h}=3 \times V_{\mathrm{p}} \times I_{\mathrm{dyn}}^{h} \times \cos (\theta),
$$

where $P_{\max }^{h}$ is decided from $P_{\mathrm{dyn}}^{h}$ by considering a safety margin.

2.7.2. Voltage Conditions of the System. The voltage constraints are introduced for the conductor section A-B at the grid end and consumer end to keep the line voltage at limits. The voltage at the consumer end of the conductor was calculated using equation (11). The actual voltage depends on whether the conductor exports or imports active and reactive power:

$$
V_{\text {consumer_end }}^{h}=V_{\text {Grid }}^{h} \pm \frac{\left(P_{\text {conductor }}^{h} \times R \mp Q_{\text {conductor }}^{h} \times X\right)}{V_{\text {Grid }}^{h}} .
$$

Under the worst case condition, the maximum voltage at the consumer end occurs, when all the power generated by the wind farm is exported, and no reactive power is absorbed from the grid. However, the minimum voltage occurs when the wind farm is not generating and active and reactive power of loads is absorbed by the grid. Therefore, the voltage constraints given in equation (12) should satisfy the voltages of A-B conductor:

$$
\begin{gathered}
\left.V_{\text {consumer_end }}^{h}\right|_{\max }=V_{\text {Grid }}^{h}+\frac{P_{\text {conductor }}^{h} \times R}{V_{\text {Grid }}^{h}} \leq V_{\max }, \\
V_{\text {min }} \leq\left. V_{\text {consumer_end }}^{h}\right|_{\text {min }}=V_{\text {Grid }}^{h}-\frac{P_{\text {conductor }}^{h} \times R+Q_{\text {conductor }}^{h} \times X}{V_{\text {Grid }}^{h}} .
\end{gathered}
$$

2.8. Modified Genetic Algorithm-Based Optimization Technique. In general, the genetic algorithm (GA) can be considered as an evolutionary algorithm in applications involving nonsmooth solution surface with discontinuities. Considering the random nature of demand loads, GA provides more accurate profiles of unmonitored consumers for analyzing purpose which gives a better solution related to user behavior and other random activities. GA-based optimization is capable of cooperating the random variables such as variations in RE generation, network capacity, user preferences, and a larger number of variables.

The basic iterative steps of the genetic algorithm are initialization evaluation, crossover, and mutation. The 
population is the set of solutions that creates the solution space and a single solution in the solution space is an individual/chromosome [38]. In the initialization step, random solutions in the cost surface are generated subjected to constraints. The crossover step involves interpolation and extrapolation of the best solutions in the piecewise solution space in search of better solutions. Then, the mutation step is used to randomly change the generated solution to a different area of the cost surface avoiding the local minima/ maxima in the solution space.

As explained in Introduction, most of the studies involving the GA have applied to a single house or a limited number of houses with controllable loads. The implementation of such a GA approach [38] failed for this case due to a large number of variables and constraints involved. Therefore, in this paper, for the appliances schedule of the smart community subjected to multiple constraints, a modified genetic algorithm (modified GA) was suggested. This modified GA is suggested as an algorithm to solve a combinatorial optimization problem which also has a dynamic feasible region of the solution space. This modified GA is capable of searching for the best solution across the nonsmooth/piecewise cost surface subjected to multiple constraints while avoiding local minima/maxima.

In Algorithm 1, the initial population of individuals/ chromosomes representing appliance schedules $(X)$ for all 24 hours per day was generated randomly based on constraints in sections $\mathrm{E}$ and $\mathrm{F}$. Considering the total demand and available renewable energy generation at each time slot $h$, the fitness value (cost of community) of each individual was calculated for each schedule using Algorithm 2. The objective function of the modified GA is given as follows:

$$
\operatorname{minimize}\left[\left(\sum_{h=1}^{T} C_{\text {community }}^{h}\right) \times \frac{24}{T}\right] .
$$

From the calculated fitness values, the half of the schedules (parents) with least values were selected and they were used to form a new crossover schedules (children). Other than the conventional genetic algorithm concept [38], here the mutation process is only executed for the children, not for the total population. A selected percentage of total appliances' time slots of operation in appliance schedules generated as children were shifted (mutation process) for another random $h$ time slot to generate a new population of appliance schedules. The mutation step was applied only for children to avoid the local maxima while keeping the best solutions in the population. After the mutation step, again the fitness value for each appliance schedule was calculated.

These steps were repeated iteratively as given in Algorithm 1 to get the optimum solution. The appliance schedule which gives the minimum fitness value within the system constraints after a number of iterations were selected as the appliance schedule of the day.

The algorithm is executed for a number of iterations in order to find the appliance schedule $\left(X_{\text {final }}\right)$ at minimum cost within the system constraints.

\section{Case Studies}

3.1. Selected Case Studies. In order to demonstrate the bestoperating scenarios of the community energy system, 8 case studies were defined. The operational parameters for each case study were selected as mentioned in Table 3 .

When the power generated by renewable energy sources is greater than the demand, the power generated from renewable energy sources are consumed by the community and any excess power generated from renewable energy sources are exported to the grid at $C_{\mathrm{RE}}^{h}$. On the other hand, if power generated by renewable energy sources is less than the demand, then additional power requirement is met by importing the power from the grid at $C_{\mathrm{G}}^{h}$.

The total cost of the community is defined based on equations (3), (4), and (5). Equation (3) represents a profit to the community, while equations (4) and (5) represent costs to the community.

Considering cost and profit conditions at each time slot $h$, the total cost to the community for a day was calculated by equation (6). $C_{\text {community }}$ was minimized using the optimization algorithm to achieve the appliance schedule at the minimum cost/maximum profit.

3.2. Parameters of the System Selected. The community system given in Figure 4 was used for case studies. It comprises 2500 houses each house with 5 shiftable appliances. The total load of the community system is $5 \mathrm{MW}$. The system owns a $10 \mathrm{MW}$ wind power generation. The optimum smart appliance schedule of the community was obtained while minimizing the cost considering the different case studies defined in Section 3.1.

3.3. Smart Appliances Power Ratings. At each house, 5 appliances were selected as smart appliances $[2,30]$. The appliance's power ratings are given in Table 4 as a matrix assuming that it is constant for 15 minutes. It was assumed that all 5 appliances must operate once per day. For the base case, it was assumed that turn on time of each appliance shows a normal distribution having a mean value and a standard deviation shown in Table 4.

3.4. Wind Farm Power Output. The total wind power generation was assumed as $10 \mathrm{MW}$ with 0.9 power factor. Twenty $500 \mathrm{~kW}$ Vestas wind turbines were selected. The power curve of a single turbine is given in Figure 5. The cutin wind speed of the turbine is $4.0 \mathrm{~m} / \mathrm{s}$, and cut-out wind speed is $25.0 \mathrm{~m} / \mathrm{s}$. It was assumed that, at a given time, they can be represented by a $10 \mathrm{MW}$ coherent generator.

Wind speed profile at wind farm considered for the case study is given in Figure 6. As it is not possible to execute the optimization algorithm within a reasonable execution time (using the PC considered) while considering the stochasticity of wind, a wind speed profile with one hour average was considered for the case study. 
(1) Set IterMax $=5000$ (maximum number of iterations)

(2) Set Iter $=1$

(3) Start

(4) Initialize population: Generate $S(S=64)$ number of $X$ random chromosomes (parents) within initialization constraints (Sections B, E, and F)

(5) while Iter $<$ IterMax do

(6) Calculate cost for each chromosome in the population: run Algorithm 2

(7) Crossover step: generate children: update population

(8) Mutation step: only for children generated (mutation rate 20\%): update population

(9) Run Algorithm 2

(10) Store minimum cost schedule $X_{\text {Iter }}$

(11) $\quad$ Iter $=$ Iter +1 ; go to 5 \{continue to the next iteration

(12) end while

(13) Store $X_{\text {final }}$ (minimum of all $X_{\text {iter }}$ )

(14) End

Algorithm 1: Main steps of the optimization algorithm.

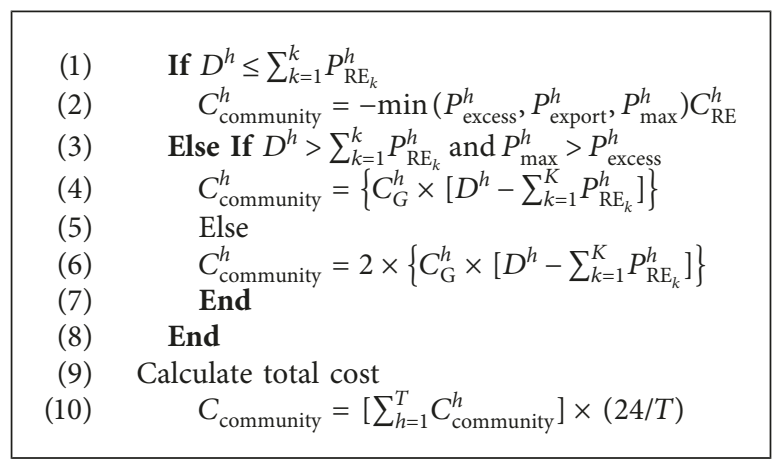

Algorithm 2: Cost calculation based on the operating mode.

TABle 3: Case studies.

\begin{tabular}{lccc}
\hline Case study & $\begin{array}{c}\text { Cost function for grid purchasing and selling } \\
\text { renewable energy }\end{array}$ & $\begin{array}{c}\text { Conductor current rating }\left(P_{\max }^{h}\right) \\
\text { Grid curtailment }\left(P_{\text {export }}^{h}\right)\end{array}$ & OFF \\
\hline 1 & & Static line rating & ON \\
3 & Economy 7 (Figure 7) & Static line rating & OFF \\
4 & & Dynamic line rating & Static line rating \\
6 & & Dynamic line rating & ON \\
7 & Economy 10 (Figure 7) & Static line rating & Dynamic line rating \\
\hline
\end{tabular}

3.5. Wind Power Selling Price and Grid Tariff. Economy 7 tariff and Economy 10 tariff that are commonly used in the UK were used as grid tariff. In these case studies, it was assumed that the cost is in a generic currency called "\#." Excess wind power generation of the system is sold to the grid at $4 \#$ less than the grid tariff. The values are given in Figure 7.

3.6. Wind Profile at the Conductor Level and Dynamic Line Rating Values. The dynamic line rating of conductor section A-B in Figure 1 was calculated using the conductor level wind profile obtained from equation (14). As the wind farm is nearby, the $1 / 7$ th rule was used to calculate the wind speed at conductor height $\left(W_{\text {conductor }}\right)$ :

$$
W_{\text {conductor }}^{h}=W_{\text {farm }}^{h} \times\left(\frac{H_{\text {conductor }}}{H_{\text {Turbine }}}\right)^{0.143} .
$$

Using the calculated $W_{\text {conductor }}^{h}$ at each hour, dynamic line rating of a selected conductor was obtained using equation (9).

3.7. Maximum Power Exported to the Grid if Grid Curtailment Is Active. For case studies 3, 4, 7, and 8, the maximum power 


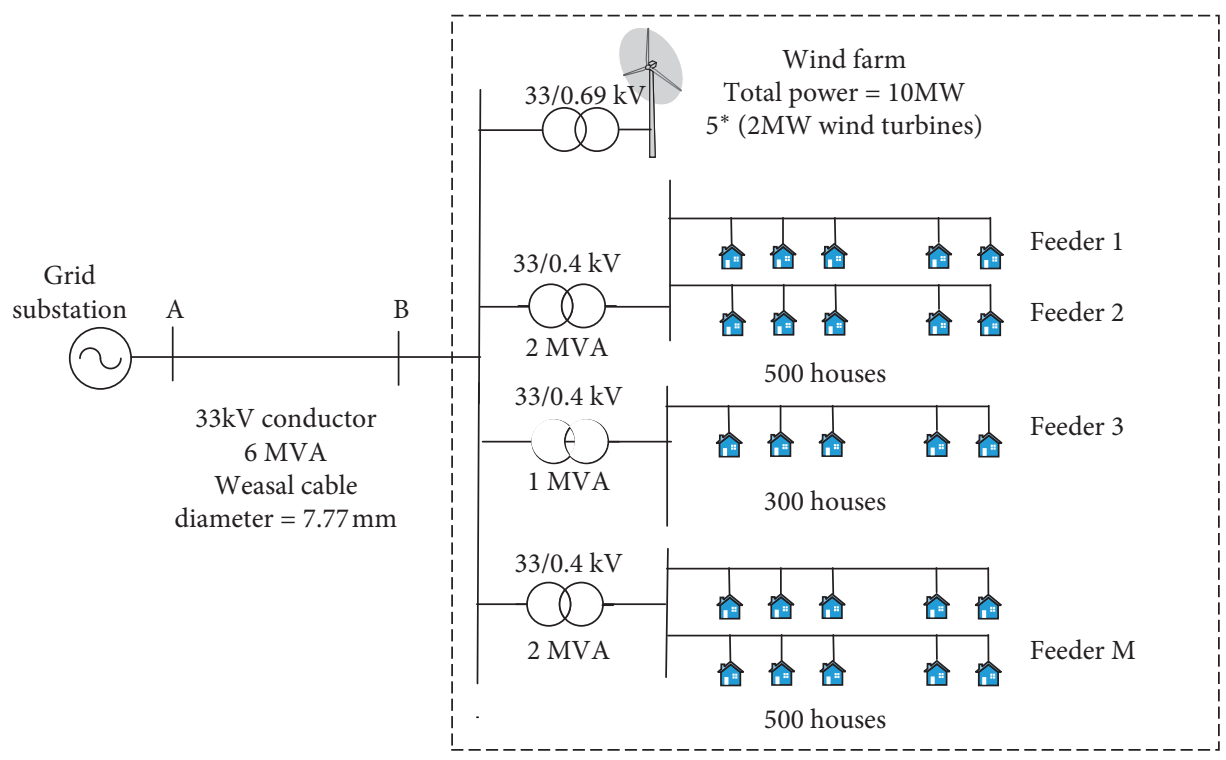

Figure 4: System parameters selected.

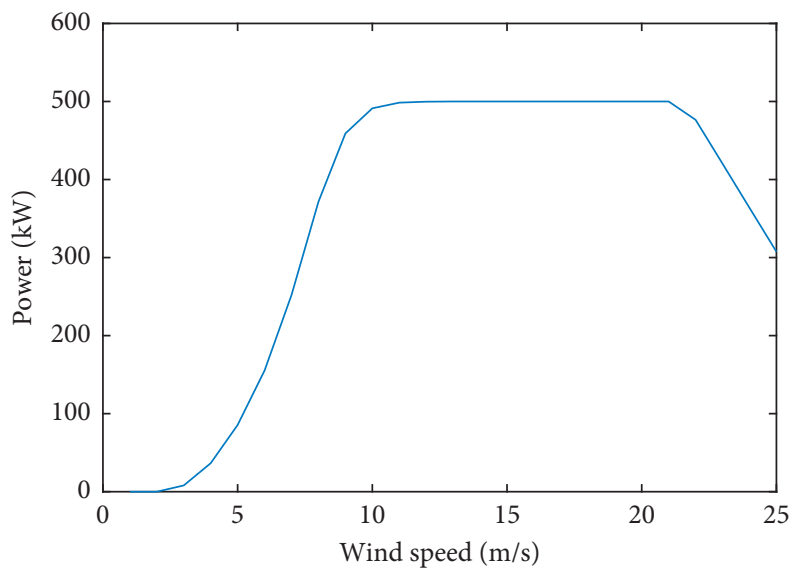

FIGURE 5: Wind turbine power curve $(500 \mathrm{~kW})$.

TABLE 4: Smart appliances' power consumption.

\begin{tabular}{|c|c|c|}
\hline Appliance & Power (W) & $\begin{array}{l}\text { Base case mean value }(\mu) \text { and standard deviation }(\sigma) \\
(\text { hrs })\end{array}$ \\
\hline Washing machine & {$\left[\begin{array}{lllllll}100 & 2000 & 900 & 100 & 100 & 400 & 50\end{array}\right]$} & $\mu=7.30$ a.m. and $\sigma=2 \mathrm{hrs}$ \\
\hline Dish washer & {$\left[\begin{array}{lllllllll}100 & 2000 & 100 & 100 & 100 & 2000 & 400 & 200\end{array}\right]$} & $\mu=9.30$ p.m. and $\sigma=2 \mathrm{hrs}$ \\
\hline Tumble dryer & {$\left[\begin{array}{llllll}2000 & 2000 & 2000 & 1600 & 1400 & 1000\end{array}\right]$} & $\mu=8.00$ a.m. and $\sigma=1.0 \mathrm{hrs}$ \\
\hline Hobs & 7600 & $\mu=5.30$ p.m. and $\sigma=4 \mathrm{hrs}$ \\
\hline Ovens & 2400 & $\mu=7.30$ p.m. and $\sigma=3 \mathrm{hrs}$ \\
\hline
\end{tabular}

values exported to the grid $\left(P_{\text {export }}^{h}\right)$ is given in Figure 8 (blue curve). For case studies 1, 2, 5, and 6, the maximum power exported to the grid is not limited and all the available wind generation is exported to the grid. This is shown by the red curve in Figure 8.

\section{Simulation Results and Discussion}

4.1. Results for the Base Case. Using the mean value and standard deviation of each appliance shown in Table 4, the base case, load profile of the community was obtained and shown in Figure 9.
Using the wind power profile generated using Figures 5 and 6 and considering static line rating and no curtailments, the cost/ profit to the community for each time interval was obtained and shown in Figure 10. The total cost to the community that was obtained for the base case is $1.5234 \times 10^{9}$ \#.

4.2. Results of the Optimization Algorithm. The appliances schedule for the day at the minimum cost of the system in Algorithm 2 for case study 1 was obtained using the optimization algorithm. The algorithm parameters used are 64 chromosomes and 5000 iterations for the study. 


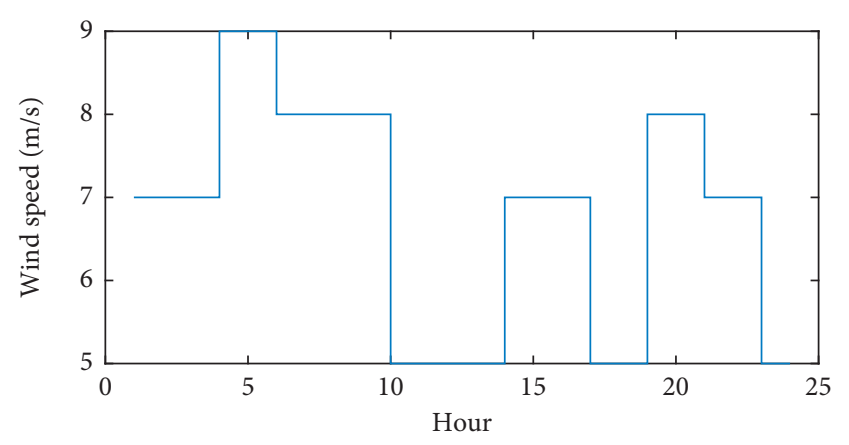

Figure 6: Wind speed at the wind farm.

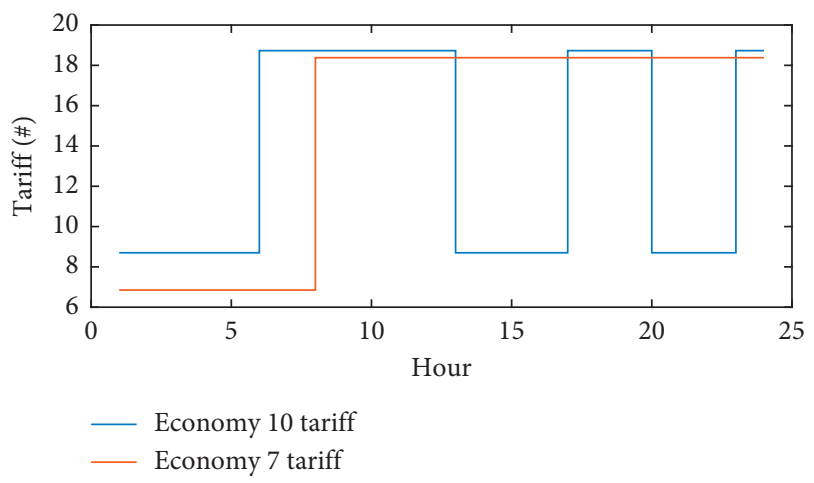

Figure 7: Wind speed at the wind farm.

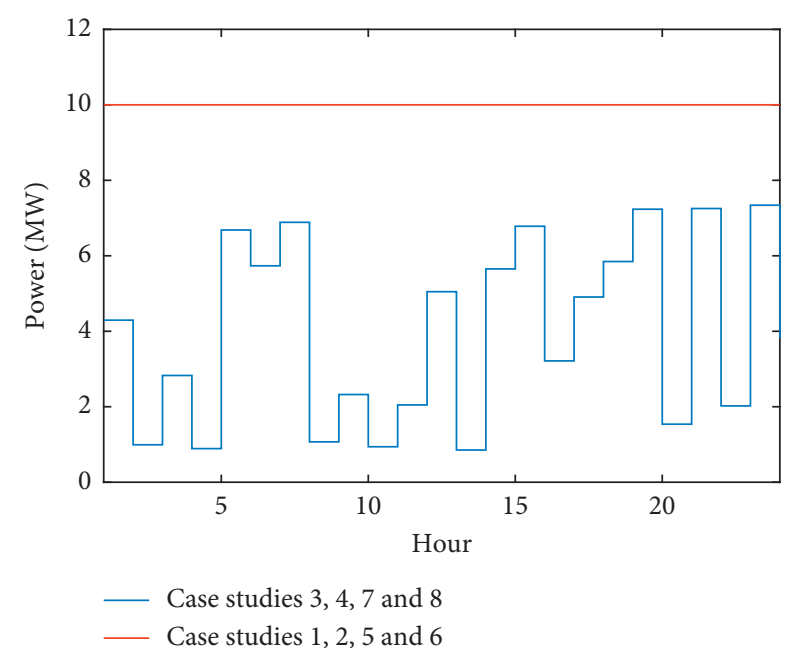

Figure 8: Maximum power exported to the grid for cases 3, 4, 7, and 8 and for cases $1,2,5$, and 6 .

The initial appliances schedule generated using the user preferences for the first 100 appliances for 20 houses in feeder 1 is given in Figure 11. The plot is only given for 100 appliances because it is not legible if all 12,500 appliances in the system are shown in a single plot. The time slot $h$ for the case studies was taken as 15 minutes.

As the input for the optimization algorithm, 64 different appliances schedules (chromosomes) were initially generated. The profits of the community at each initial appliance schedule are given in Figure 12.

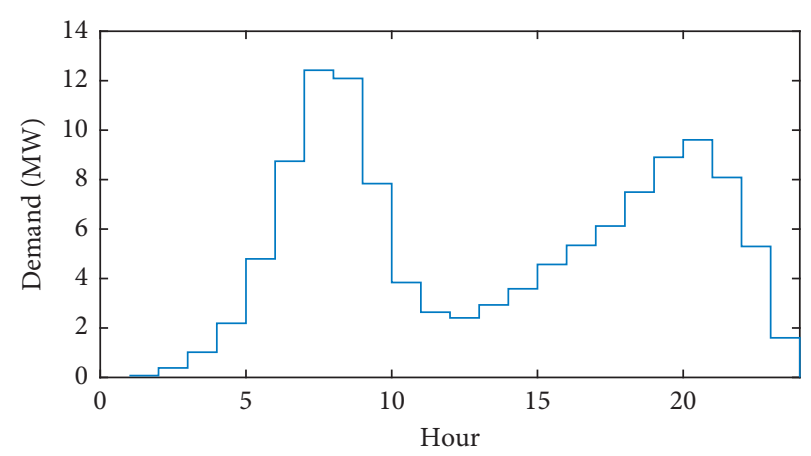

FIgURE 9: Demand of the community.

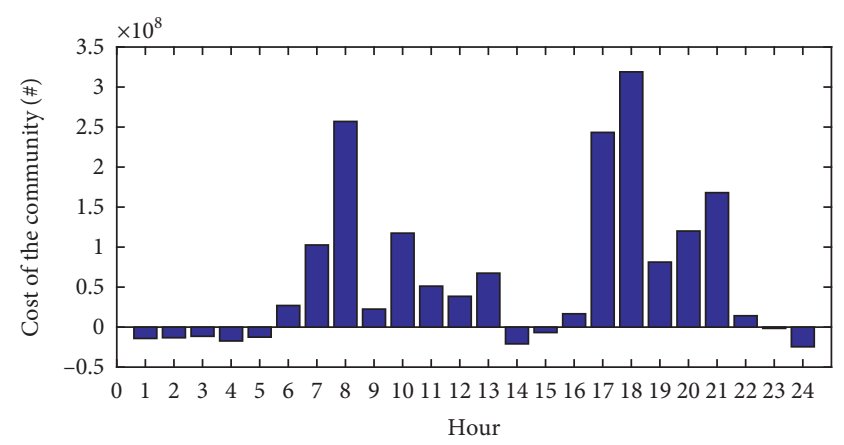

FIgURE 10: Cost of the community at each hour for the base case.

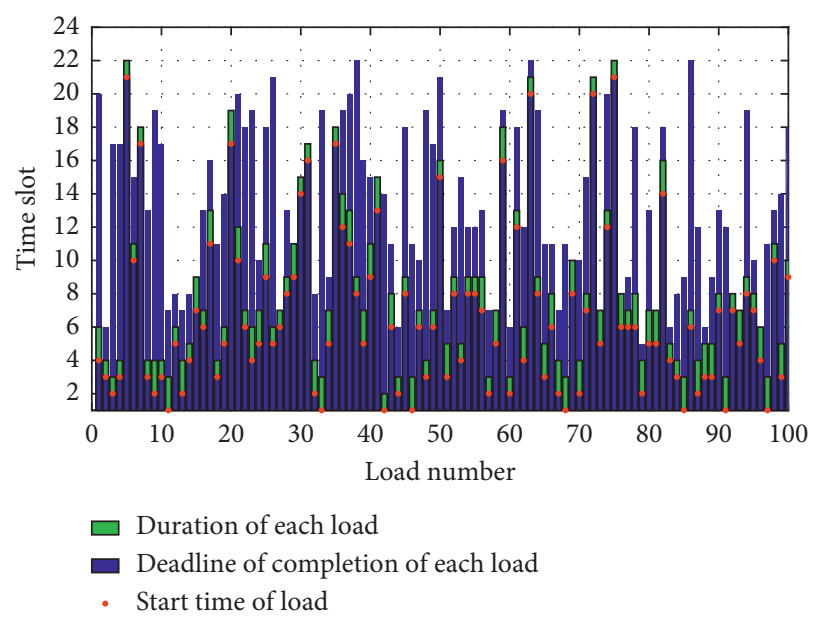

FIGURE 11: Initial appliance schedule for 100 appliances with the deadline of completion of the load, duration of load, and start time.

The profit of the community for 5000 iterations with the crossover and mutation steps of the optimization algorithm (given Algorithm 2) is shown in Figure 13. This figure shows the maximum profit out of 64 chromosomes at each iteration. After 5000 iterations, it was observed that the profit of the community converges to more or less a maximum. The appliances schedule at a maximum profit (minimum cost) at the 5000th iteration is given in Figure 14 for the 100 appliances shown in Figure 11 along with the starting time slot of each appliance to achieve the maximum profit. Figure 15 shows the profit of the community for all 64 chromosomes at the 5000th iteration. 


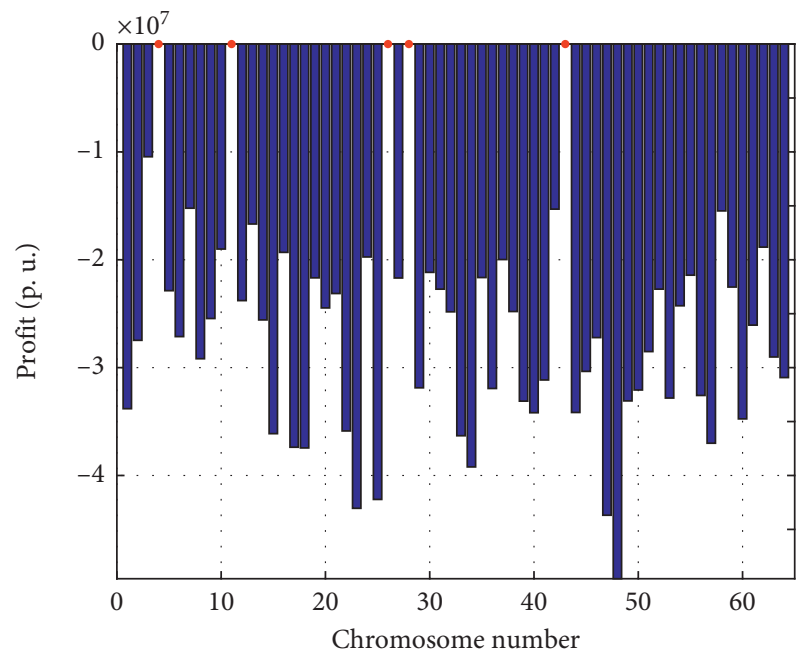

Figure 12: Profit of community at each chromosome at iteration 1.

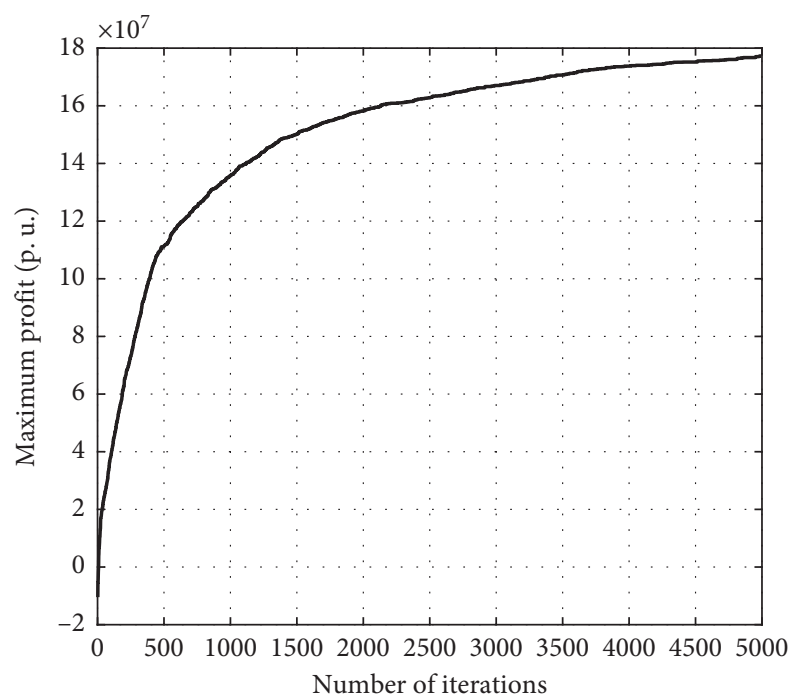

FIGURE 13: Profit of the community for 5000 iterations (termination condition).

The conductor static line rating was used as the maximum current capacity of A-B conductor for this case study. The static power rating and the power flow in conductor $\mathrm{A}-\mathrm{B}$ when the smart community is operating at the maximum profit are given in Figure 16.

The scheduled demand of the community at the optimum appliance schedule obtained from the algorithm together with the grid tariff and wind generation selling price is shown in Figure 17.

For case study 2 where the maximum power flow of A-B conductor is the dynamic line rating which varies with the wind speed, the power flow of the A-B conductor at the optimum appliance schedule is given in Figure 18.

4.3. Maximum Profit of Case Studies. For case studies 1-4, the profit values for 5000 iterations of the optimization algorithm are shown in Figure 19(a). For case studies 5-8, the profit values for 5000 iterations of the optimization algorithm are shown in Figure 19(b).

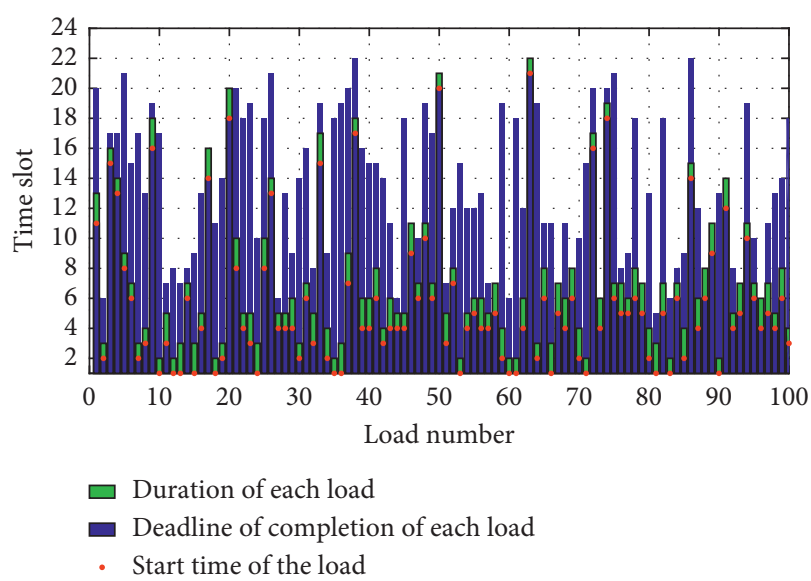

FIgURE 14: Maximum profit appliance schedule.

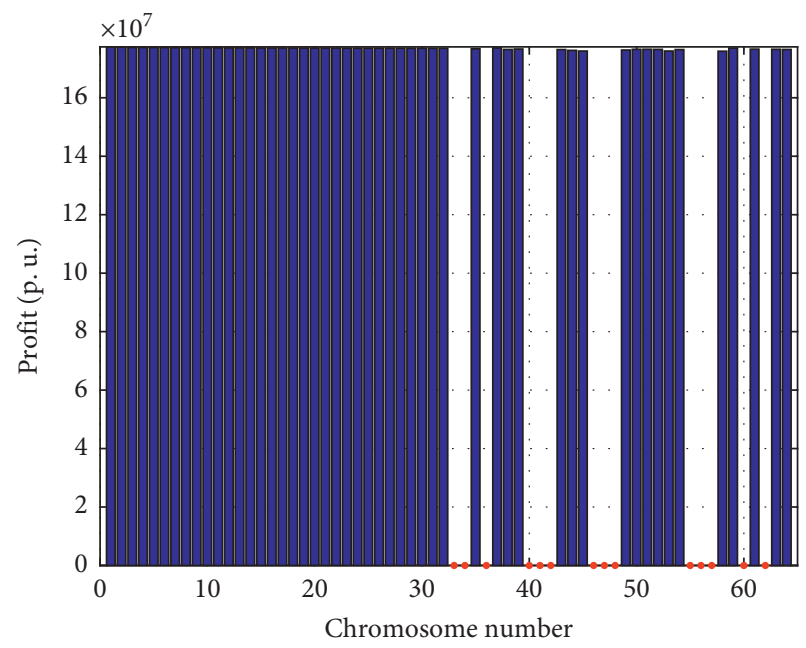

Figure 15: Profit of 64 chromosomes at the 5000th iteration.

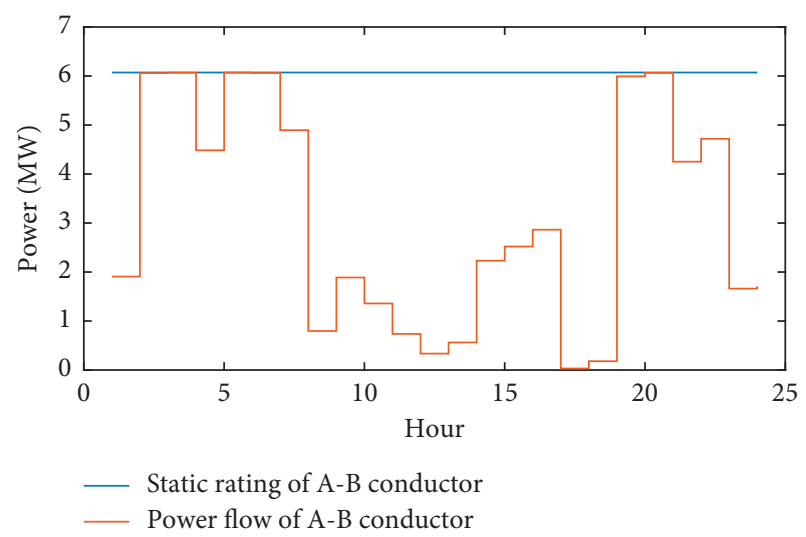

FIGURE 16: Static power rating of the conductor and the power flow of the conductor when the system is operated at case study 1 .

According to obtained appliances schedule, the power flow in the A-B conductor for cases 1, 2, 3, and 4 is given in Figure 20(a). The static and dynamic line ratings are also shown. A-B conductor power flow for case studies $5,6,7$, and 8 is shown in Figure 20(b). The demand of the smart 


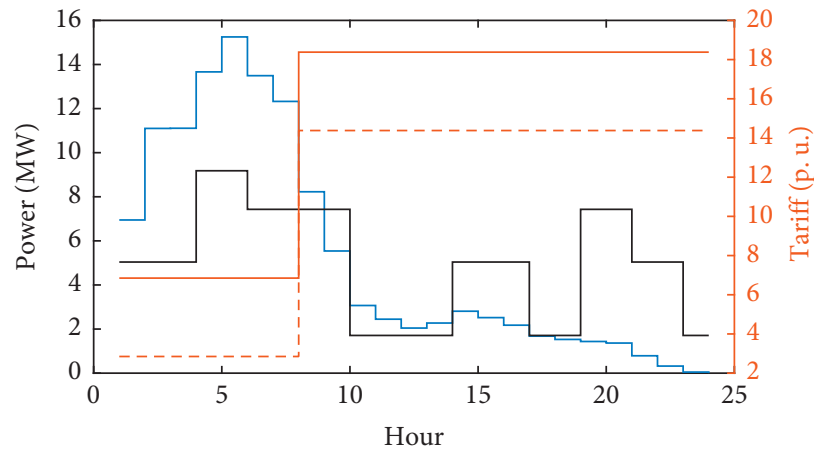

Demand of the community
_ Wind power generation
_ Grid tariff
- - Wind generation selling price

Figure 17: Demand of the community, wind power generation, grid tariff, and wind generation selling price at case study 1.

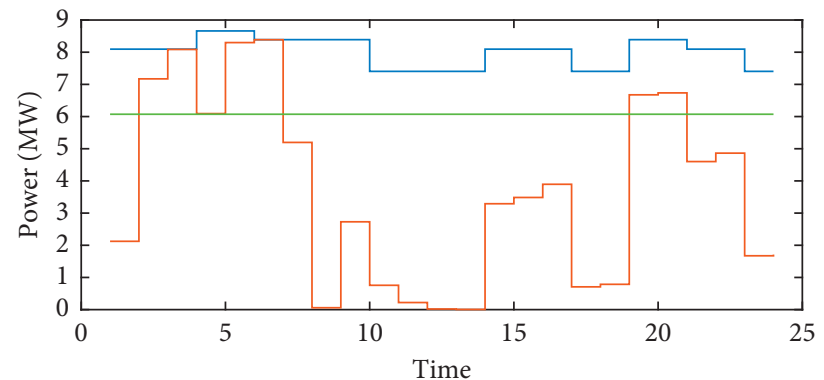

Dynamic power rating
Power flow of the cable
Static power rating

FIgURE 18: Dynamic power rating of the conductor, static power rating, and the power flow of the conductor when the system is operated at case study.

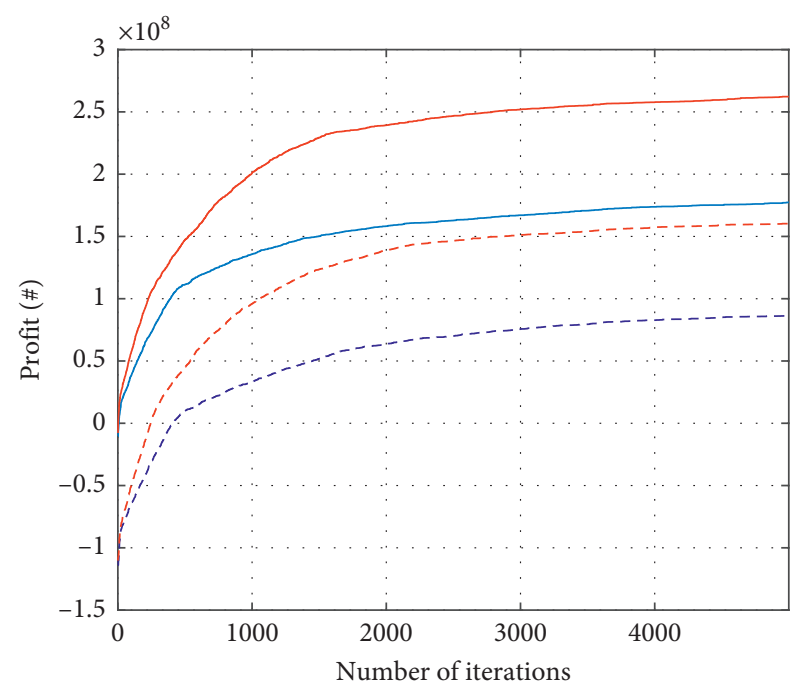

- Case 1
- - - Case 3

- - Case 4

(a)

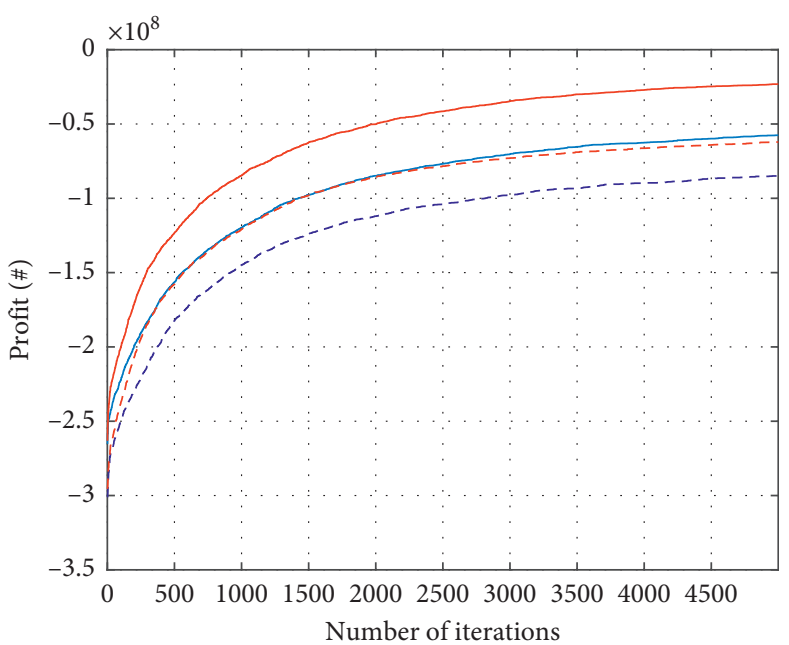

- Case 5

_ Case 6$$
\text { Case } 8
$$

(b)

Figure 19: Profit of the community for (a) case studies 1-4 (grid tariff is Economy 7) and (b) case studies 5-8 (grid tariff is Economy 10). 


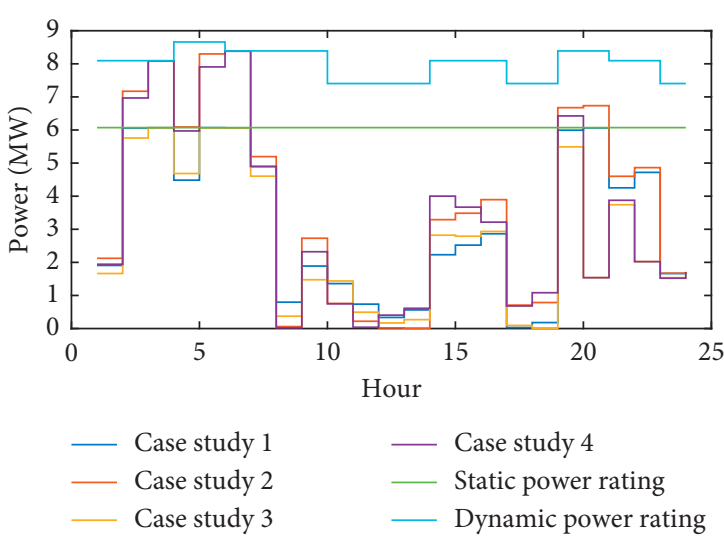

(a)

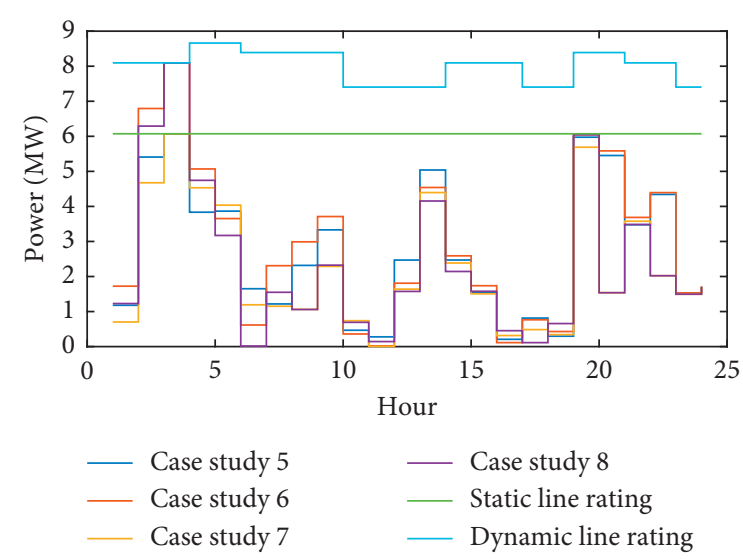

(b)

Figure 20: A-B conductor power flow for case studies, static line rating, and dynamic line rating: (a) case studies 1, 2, 3, and 4; (b) case studies $5,6,7$, and 8 .

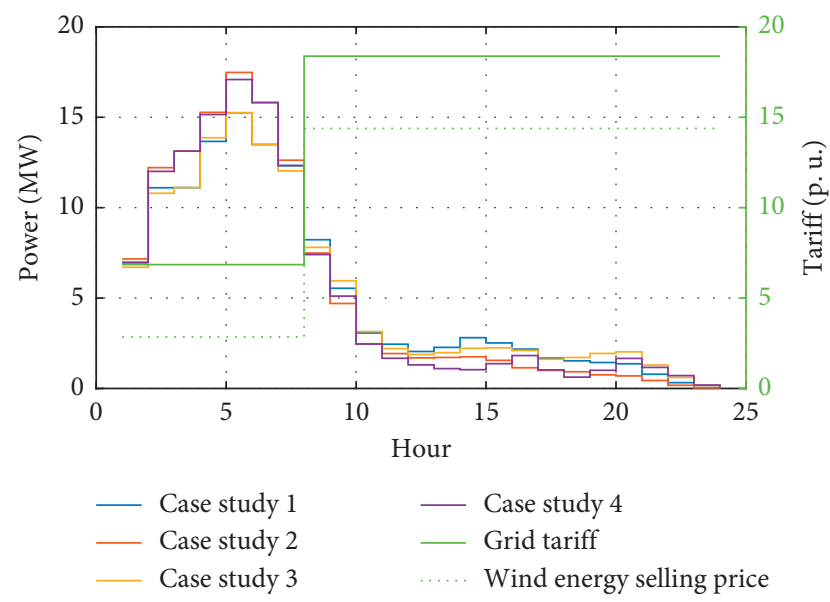

(a)

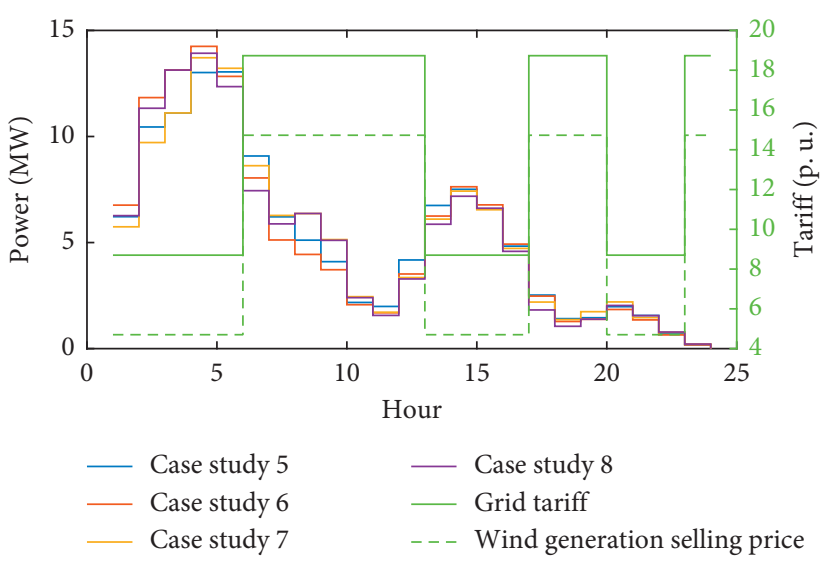

(b)

Figure 21: Demand of the community, grid tariff, and wind generation selling price for case studies (a) 1, 2, 3, and 4 and (b) 5, 6, 7, and 8 .

community at the optimum appliance schedule for studies 1 , 2, 3, and 4 is given in Figure 21(a). The demand of the smart community at the optimum appliance schedule for case studies 5, 6, 7 and 8 is given in Figure 21(b).

\subsection{Comparison of Profit with Dynamic Line Rating and Static} Line Rating. The optimum appliance schedules were obtained considering real wind speed measurements at a wind farm in California. The wind profile for seven days is given in Figure 22. The profit of the community for each day when the base case load profile was used with the static rating of the conductor, the optimum load schedule with the static rating of the conductor, and optimum load schedule with dynamic rating of the conductor are shown in Figure 23.

Figure 23 clearly shows that when the smart appliances of the community are scheduled optimally using the suggested algorithm, the profit of the community was maximized. This can be clearly seen when one compares the base case profit with the profit for optimum scheduling. The profit can be further increased if the dynamic rating of the

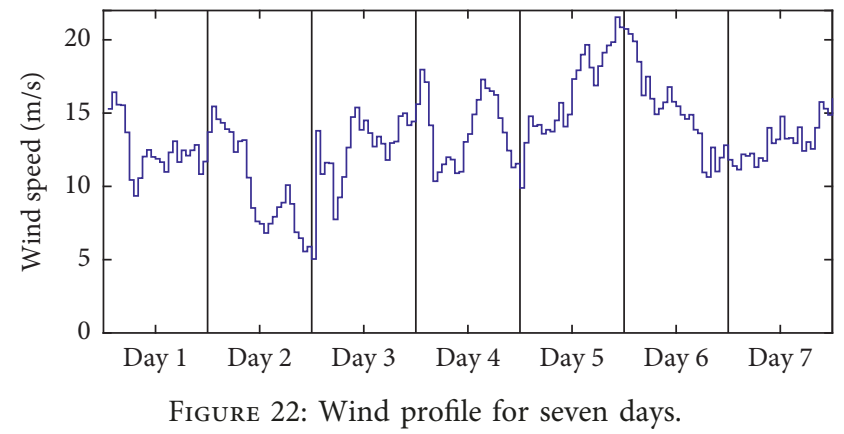

line that connects the community system to the grid is considered.

\section{Discussion}

As discussed in Section 2.8, when compared to the conventional genetic algorithm concept [38], in the modified GA, the mutation process is only executed for the children, not for the total population. In order to demonstrate the 


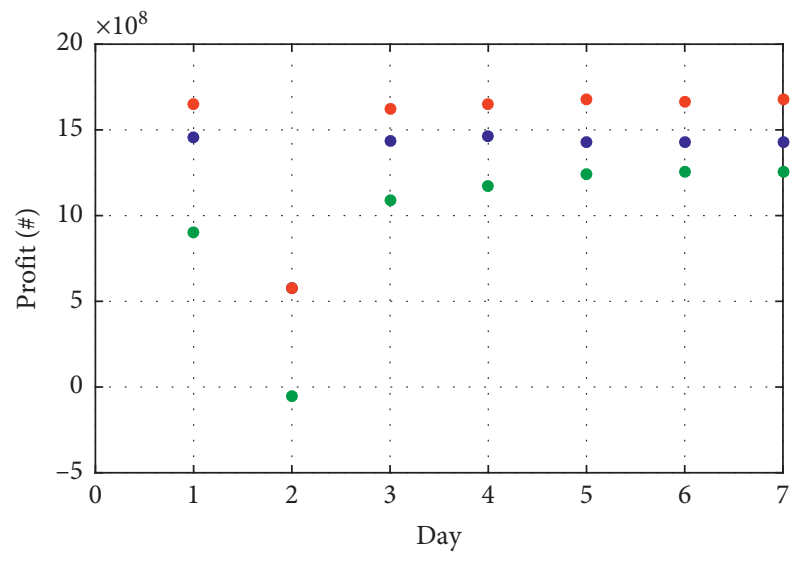

- Appliance scheduling with cable's static rating

- Appliance scheduling with cable's dynamic rating

- Base case

Figure 23: Profit of community for seven days given in Figure 22.

performance of the modified GA, the optimization results for case study 1 ( 64 chromosomes and 2000 iterations) using both the conventional GA [38] and modified GA were performed, and results are given in Table 5 . As can be seen, the modified GA is much faster than the conventional algorithm and provides better optimization result.

Even though the modified GA is trying to optimize the profit to the community, in turn, it increases the utilization of the renewable energy sources within the community, thus providing added benefits in terms of $\mathrm{CO}_{2}$ reductions.

\section{Conclusions}

The maximum profit of the smart community which produces renewable energy on their own is achieved by introducing an optimum appliance schedule while maximizing the renewable energy usage within operational constraints. A generalized methodology was developed that can be applied to optimize the profit of a smart community for different operating modes based on the availability of renewable generation, wind speed, tariff, grid curtailment, conductor current capacity, and other system constraints. This method ensures the user comfort as it satisfies the user preferences on smart appliance operating times, maximizes the profit to the community, and provides benefits to the society as it allows maximum use of the renewable energy sources within the community energy system.

The simulation results obtained from the case studies show that the introduction of the optimum scheduling while considering the dynamic line rating as a system constraint increases the profit of the community nearly by 1.5 -fold. The average simulation time required to obtain the optimum solution with 12,500 controllable entities was 2000s. Even though it is not included in this paper, the authors have already developed a sensor network to determine the dynamic line rating, and integration of different algorithms and field testing are in progress.

TABLE 5: Comparisons of optimization algorithms.

\begin{tabular}{lcc}
\hline Matric & $\begin{array}{c}\text { Conventional GA (mutation applied for } \\
\text { total population) }\end{array}$ & $\begin{array}{c}\text { Modified } \\
\text { GA }\end{array}$ \\
\hline $\begin{array}{l}\text { Execution } \\
\text { time }\end{array}$ & $25400 \mathrm{~s}$ & $2392 \mathrm{~s}$ \\
$\begin{array}{l}\text { Optimized } \\
\text { profit }\end{array}$ & $3.28 \times 10^{7}$ & $4.07 \times 10^{7}$ \\
\hline
\end{tabular}

In this study, the parameters such as conductor current carrying capacity and voltage limits were considered. This is a limitation of the study as there are other parameters that impact the optimum operation and reliability of the community energy systems.

\section{Nomenclature}

$a_{n}^{y}:$

$x_{a_{n}^{y}}^{h}:$

$P_{y, n}^{h}:$

$P_{\mathrm{RE}_{k}}^{h}$ :

$C_{\mathrm{RE}}^{h}$ :

$C_{\text {community: }}^{h}$ :

$C_{\text {community: }}$

$P_{\mathrm{G}}^{h}$ :

$C_{\mathrm{G}}^{h}:$
$P_{\text {conductor_sell }}^{h}:$

$P_{\text {conductor_buy }}^{h}$ :

$P_{\text {conductor }}^{h}, Q_{\text {conductor }}^{h}$ :

$P_{\text {max }}^{h}$ :

$P_{\text {dyn }}^{h}:$

$I_{\text {dyn }}^{h}$ :

$I^{h}:$

$V_{\text {consumer_end: }}^{h}$ :

$V_{\text {Grid }}^{h}$ :

$R$ and $X$ :

$h_{\text {start }}$ and $h_{\text {stop }}$ :

$P_{\mathrm{RE}_{k}, \max }^{h}$ :

$P_{\mathrm{RE}_{k}, \min }^{h}$ :

$P_{\text {export: }}^{h}$ : $y$ th appliance of the $n$th house ON/OFF state of the $a_{n}^{y}$ th appliance at time slot $h$.

Average power consumption of appliance $a_{n}^{y}$ at time slot $h$.

Average power generated by the $k$ th renewable energy source at time slot $h$ Renewable source purchasing tariff at time slot $h$

Cost of community at time slot $h$

Total cost of community for 24 hours Average power imported to community from grid at time slot $h$ Grid tariff at time slot $h$

Renewable power sold to grid at time slot $h$

Power purchased from grid at time slot $h$

Active and reactive power flow of the conductor at time slot $h$

Maximum power rating of the conductor at time slot $h$

Power flow when the conductor has $I_{\text {dyn }}^{h}$ current rating

Dynamic line rating of the conductor at time slot $h$

Current flow of conductor A-B at time slot $h$

Voltage of the conductor at consumer end at time slot $h$

Voltage of the conductor at grid end at time slot $h$

Line resistance and reactance of the conductor

Start and stop time limit of an smart appliance

Maximum generation capacity of the $k$ th renewable source at time slot $h$ Minimum generation capacity of the $k$ th renewable source at time slot $h$ Maximum power exported to grid from community renewable energy sources 


$R_{\mathrm{dc}}:$
$\alpha_{0}:$
$T_{\text {max }}:$
$T_{0}:$
$D:$
$\lambda:$
$k_{\mathrm{wd}}:$
$T_{\mathrm{a}}^{h}:$
$\varepsilon:$
$\sigma:$
$S_{\mathrm{d}}:$
$S_{\mathrm{b}}:$
$\alpha_{\mathrm{s}}:$
$V_{\mathrm{f}}:$
$W_{\text {conductor }}^{h}:$
$V_{\mathrm{p}}:$
$\Theta^{\Theta}$
$W_{\text {farm }}:$
$H_{\text {conductor }}:$
$H_{\text {turbine }}:$
$V_{\text {min }}:$
$V_{\text {max }}:$

\section{Data Availability}

The data for the case study are given in the sections of the paper including the references section. All the other data used for the simulations can be obtained from the corresponding author upon request.

\section{Conflicts of Interest}

The authors declare that there are no conflicts of interest regarding the publication of this paper.

\section{Acknowledgments}

The authors would like to acknowledge the financial support provided by Sri Lanka Technological Campus, Padduka, Sri Lanka.

\section{References}

[1] Department for Business, Energy and Industrial Strategy, Guidance Community Energy, Department for Business, Energy and Industrial Strategy, London, UK, 2015.

[2] T. Rajeev and S. Ashok, "Dynamic load-shifting program based on a cloud computing framework to support the integration of renewable energy sources," Applied Energy, vol. 146, pp. 141-149, 2015.

[3] O. G. A. Eiji and K. Akihiro, "Social system demonstration of dynamic pricing in the Kitakyushu smart community creation project," Fuji Electric Review, vol. 59, no. 3, pp. 152-160, 2013.

[4] K. Smart and C. Creation, Result of the Kitakyushu Smart Community Creation, Fuji Electric Co., Ltd., Tokyo, Japan, 2015.

[5] Y. Cai, T. Huang, E. Bompard, Y. Cao, and Y. Li, "Selfsustainable community of electricity prosumers in the emerging distribution system," IEEE Transactions on Smart Grid, vol. 8, no. 5, pp. 2207-2216, 2017.

[6] N. Yu, L. Mu, Y. Miao, H. Huang, H. Du, and X. Jia, "Distributed load scheduling in smart community with capacity constrained local power supplier," in Proceedings of the 2015 IEEE 34th International Performance Computing and Communications Conference IPCCC 2015, pp. 8590-8599, Nanjing, China, December 2016.

[7] S. Nan, M. Zhou, and G. Li, "Optimal residential community demand response scheduling in smart grid," Applied Energy, vol. 210, pp. 1280-1289, 2018.

[8] J. Zhou, R. Q. Hu, X. Zhang, and Y. Qian, "Price and output control in a community power network with renewable generations," in Proceedings of the 2012 IEEE Third International Conference on Smart Grid Communications SmartGridComm 2012, pp. 576-580, Tainan, Taiwan, November 2012 .

[9] P. kounnos Seksak Pholboon and M. Sumner, "Community power flow control for peak demand reduction and energy cost savings," in Proceedings of the 2016 IEEE PES Innovative Smart Grid Technologies Conference Europe (ISGT-Europe), Ljubljana, Slovenia, October 2016.

[10] Y. Yaseen and B. Ghita, "Peak-to-average reduction by community-based DSM," in Proceedings of the 2017 5th IEEE International Conference on Smart Energy Grid Engineering SEGE 2017, pp. 194-199, Oshawa, Canada, August 2017.

[11] F. Ye, Y. Qian, and R. Q. Hu, "A real-time information based demand-side management system in smart grid," IEEE Transactions on Parallel and Distributed Systems, vol. 27, no. 2, pp. 329-339, 2016.

[12] A. Fazeli, M. Sumner, E. Christopher, and M. Johnson, "Power flow control for power and voltage management in future smart energy communities," in Proceedings of the $3 \mathrm{rd}$ Renewable Power Generation Conference (RPG 2014), pp. 1-6, Naples, Italy, September 2014.

[13] P. Olivella-Rosell, E. Bullich-Massagué, M. Aragüés-Peñalba et al., "Optimization problem for meeting distribution system operator requests in local flexibility markets with distributed energy resources," Applied Energy, vol. 210, pp. 881-895, Jan. 2018.

[14] A. J. D. Rathnayaka, V. M. Potdar, T. Dillon, and S. Kuruppu, "Framework to manage multiple goals in community-based energy sharing network in smart grid," International Journal of Electrical Power and Energy Systems, vol. 73, pp. 615-624, 2015.

[15] P. Alvina, X. Bai, Y. Chang, D. Liang, K. Lee, and P. Ferrão, "Smart community based solution for energy management," Energy Procedia, vol. 143, pp. 635-640, 2017.

[16] Y. Zhou, C. Wang, J. Wu, J. Wang, M. Cheng, and G. Li, "Optimal scheduling of aggregated thermostatically controlled loads with renewable generation in the intraday electricity market," Applied Energy, vol. 188, pp. 456-465, 2017.

[17] E. Reihani, S. Sepasi, and R. Ghorbani, "Scheduling of pricesensitive residential storage devices and loads with thermal inertia in distribution grid," Applied Energy, vol. 183, pp. 636-644, 2016.

[18] X. Wang, A. Palazoglu, and N. H. El-Farra, "Operational optimization and demand response of hybrid renewable energy systems," Applied Energy, vol. 143, pp. 324-335, 2015.

[19] Y. Liang, F. Liu, C. Wang, and S. Mei, "Distributed demandside energy management scheme in residential smart grids: an ordinal state-based potential game approach," Applied Energy, vol. 206, pp. 991-1008, 2017. 
[20] E. Matallanas, M. Castillo-Cagigal, A. Gutiérrez et al., "Neural network controller for Active Demand-Side Management with PV energy in the residential sector," Applied Energy, vol. 91, no. 1, pp. 90-97, 2012.

[21] F. Shahnia, M. T. Wishart, A. Ghosh, G. Ledwich, and F. Zare, "Smart demand side management of low-voltage distribution networks using multi-objective decision making," IET Generation, Transmission and Distribution, vol. 6, no. 10, p. 986, 2012.

[22] N. Liu, M. Cheng, X. Yu, J. Zhong, and J. Lei, "Energy-sharing provider for PV prosumer clusters: a hybrid approach using stochastic programming and stackelberg game," IEEE Transactions on Industrial Electronics, vol. 65, no. 8, pp. 6740-6750, 2018.

[23] J. Soares, M. A. Fotouhi Ghazvini, M. Silva, and Z. Vale, "Multi-dimensional signaling method for population-based metaheuristics: solving the large-scale scheduling problem in smart grids," Swarm and Evolutionary Computation, vol. 29, pp. 13-32, 2016.

[24] J. Widén, "Improved photovoltaic self-consumption with appliance scheduling in 200 single-family buildings," Applied Energy, vol. 126, pp. 199-212, 2014.

[25] H. Shi, N. Blaauwbroek, P. H. Nguyen, and R. Kamphuis, "Energy management in multi-commodity smart energy systems with a greedy approach," Applied Energy, vol. 167, pp. 385-396, 2016.

[26] H. A. Mostafa, R. El Shatshat, and M. M. A. Salama, "Optimal distribution systems operation using smart matching scheme (SMS) for smart grid applications," IEEE Transactions on Smart Grid, vol. 5, no. 4, pp. 1938-1948, 2014.

[27] M. Stötzer, I. Hauer, M. Richter, and Z. A. Styczynski, "Potential of demand side integration to maximize use of renewable energy sources in Germany," Applied Energy, vol. 146, pp. 344-352, 2015.

[28] Y. F. Du, L. Jiang, Y. Z. Li, J. Counsell, and J. S. Smith, "Multiobjective demand side scheduling considering the operational safety of appliances," Applied Energy, vol. 179, pp. 864-874, 2016.

[29] T. M. Hansen, R. Roche, S. Suryanarayanan, A. A. Maciejewski, and H. J. Siegel, "Heuristic optimization for an aggregatorbased resource allocation in the smart grid," IEEE Transactions on Smart Grid, vol. 6, no. 4, pp. 1785-1794, 2015.

[30] S. Nistor, Residential demand response in the power system, Ph.D. dissertation, School of Engineering, Cardiff University, Cardiff, UK, 2014.

[31] O. H. Abdalla, R. Al-Badwawi, H. Al-Hadi, H. Al-Riyami, and A. Al-Nadabi, Weather-Based Ampacity of Overhead Transmission Lines, 2013.

[32] M. Saffari, A. de Gracia, C. Fernández, M. Belusko, D. Boer, and L. F. Cabeza, "Optimized demand side management (DSM) of peak electricity demand by coupling low temperature thermal energy storage (TES) and solar PV," Applied Energy, vol. 211, pp. 604-616, October 2017-2018.

[33] Hydro Tasmania Consulting, "Dynamic transmission line rating," in Proceedings of the Technology Review 208478-NaN-1, Tasmania, Australia, July 2009.

[34] R. Adapa and D. A. Douglass, "Dynamic thermal ratings: Monitors and calculation methods," in Proceedings of the Inaugural IEEE PES 2005 Conference and Exposition in Africa, pp. 163-167, Durban, South Africa, July 2005.

[35] IEEE Power Engineering Society, IEEE Standard for Calculating the Current-Temperature Relationship of Bare Overhead Conductors, Vol. 2006, IEEE Power Engineering Society, Piscataway, NJ, USA, 2013.
[36] IEEE standard for calculating the current-temperature relationship of bare overhead conductors," IEEE Std 738-1993, 1993.

[37] A. H. Wijethunga, J. V. Wijayakulasooriya, J. B. Ekanayake, and N. De Silva, "Conductor temperature based low cost solution for dynamic line rating calculation of power distribution lines," in Proceedings of the 2015 IEEE 10th International Conference on Industrial and Information Systems (ICIIS), pp. 128-133, Peradeniya, Sri Lanka, December 2015.

[38] J. Branke, Evolutionary Optimization in Dynamic Environments, Vol. 3, Springer US, New York, NY, USA, 2002. 


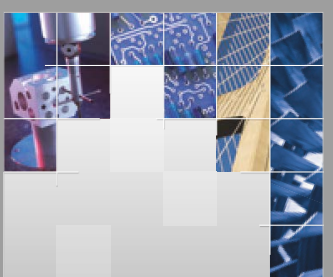

\section{Enfincering}
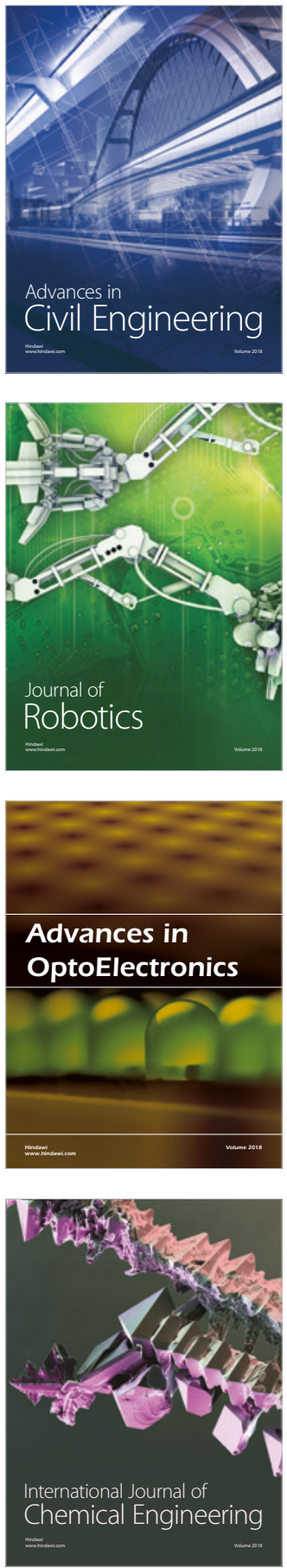

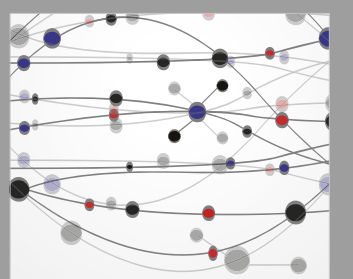

\section{Rotating \\ Machinery}

The Scientific World Journal

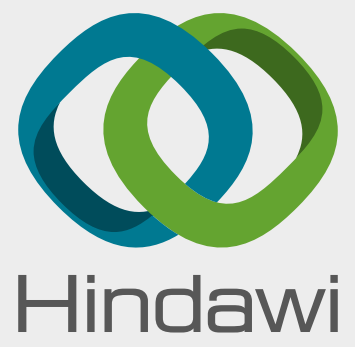

Submit your manuscripts at

www.hindawi.com
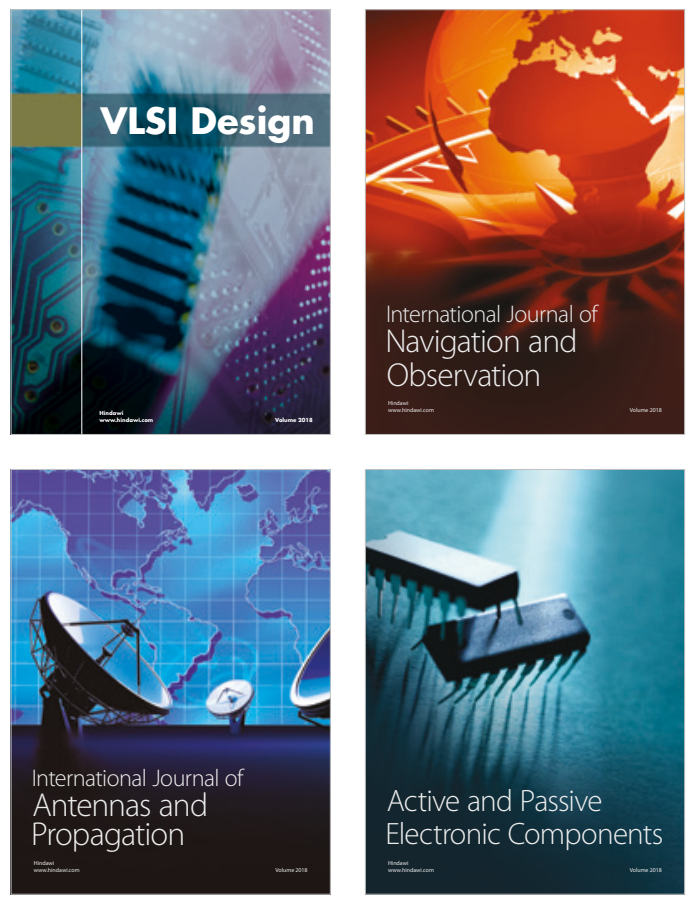
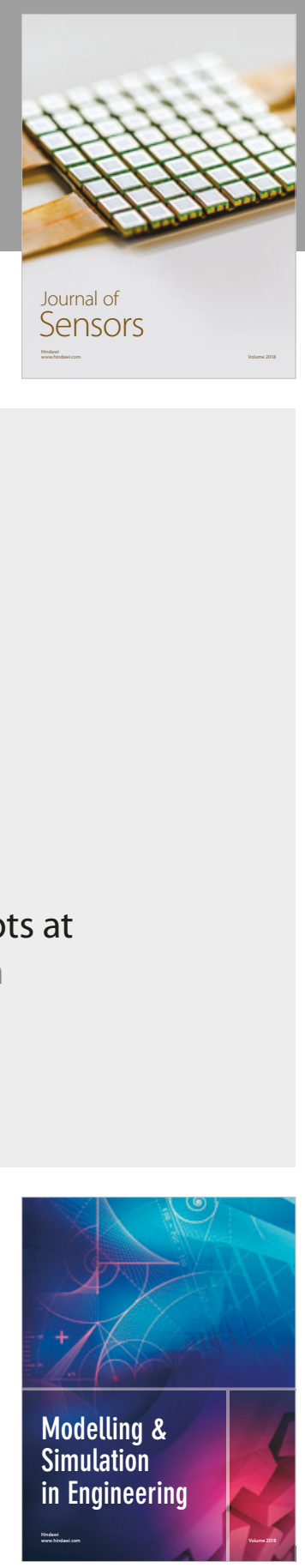

\section{Advances \\ Multimedia}
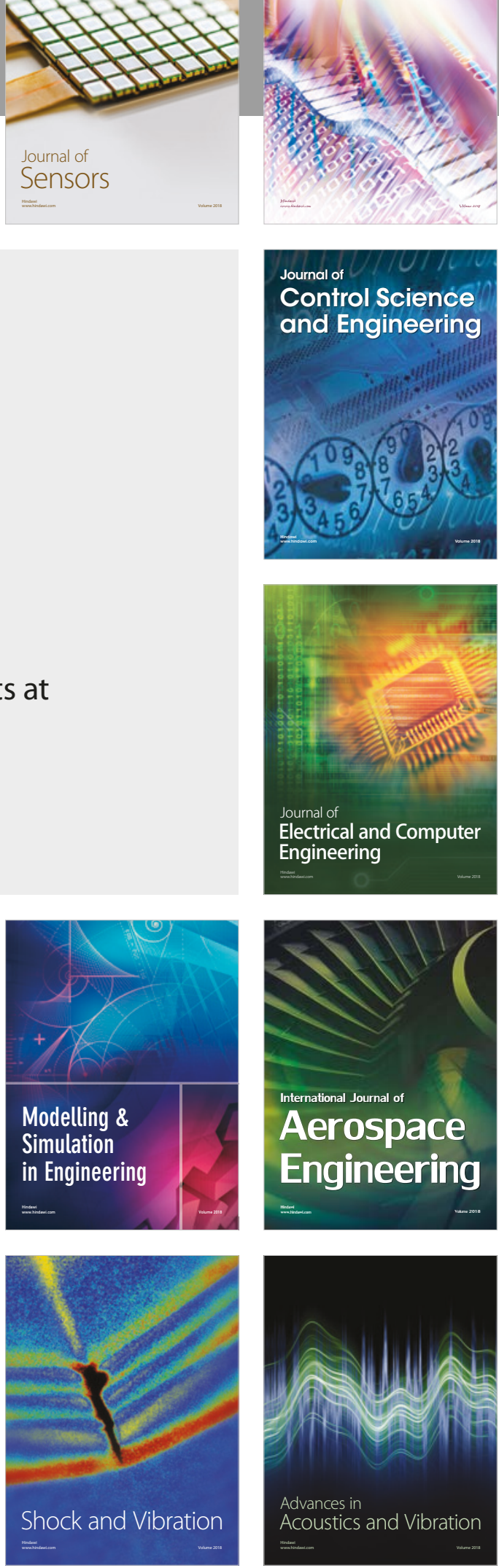